\title{
Economic Valuation of the Sundarbans Reserved Forest of Bangladesh: The Zonal Travel Cost Method
}

\begin{abstract}
Sundarbans Reserved Forest hosts the largest single block of tidal, salt-water mangrove forest on Earth with a diverse collection of flora and fauna, including many endangered ones. It is thus, (and also generally) necessary to find an appropriate estimation of the recreational benefits of this world-renowned region as a tool for the conservation of biodiversity, as well as the development of ecotourism, there. This report has been designed to do just that (estimate the recreational value) and to exhibit a relationship between the Sundarbans Reserved Forest (SRF) in Bangladesh and travel cost, using the responses of the visitors to this region from all over Bangladesh. A zonal approach of the travel cost technique has been used here and the sample was 300 visitors of SRF over a period of seven days. The analysis yielded that the total value of the environmental resources of SRF is around 197 million Tk./year. A suggestion has also been made of initiating an entrance fee of 50 Tk./person/visit which could generate proceeds of approximately 5,000,000 Tk./year, to successfully fulfill the duties of the mangrove area management and biodiversity conservation.
\end{abstract}

[Raisa Bashar]

Keywords - travel cost, valuation, Sundarbans

\section{Introduction and} Background of Research

Sundarbans is one of the biggest examples of human exploitation on forests and its flora and fauna in the world. Unfortunately, by the late 1980s, this amazingly diverse and resource-rich eco-region had lost almost $60 \%$ of the forest land along with the animals and plants residing there (Guha and Ghosh, 2009). Sundarbans is also home to the largest mangrove forest on Earth and the Royal Bengal Tigers, which are a highly endangered species roaming around in this 1990s-declared Tiger Reserve. Even though there are awareness campaigns and strict laws against both the poaching of tigers and harming their natural habitats, their numbers keep dwindling due to a number of reasons, including issues between the locals and management, low levels of monitoring, inefficient and poor management facilities, corruption amongst law officials, lack of information on the importance of these land areas among the general public, etc. (Mukul, 2007).

Raisa Bashar

Environmental Science and Management department North South University, Bangladesh
Forest reserves, national parks and animal sanctuaries are established by environmental organizations to conserve the rich biodiversity of a particular eco-region and also prevent its flora and fauna from facing further depletion from human activities (Reeves, 2000). However, that is not enough. It is also important to put a value on these natural resources and, if possible, the reserve as a whole to develop the sector of ecotourism (Farnham, 2007), which in turn produces revenues to better manage the reserves (Khan, 2004), and also, to establish both physical and official infrastructure to better protect these important parts from further destruction (Rana et al., 2010). Unfortunately, for our generation, not much research has been done in this area and definitely not in the context of Bangladesh which actually holds around $20 \%$ more of this forest area than our neighbors with whom we share the Sundarbans, India. Keeping this gap in the literature in mind and with the desire of producing a proper value for the Sundarbans Reserved Forest (SRF) from the viewpoint of the Bangladeshi people, this research aims to use travel cost valuation technique to put an economic value on SRF. The responses of national visitors to this area have been used to establish the value after much analysis. In addition, their willingness to pay to protect the SFR played the dominant role in providing a value for a proposed entry-fee.

Furthermore, an economic valuation of SRF is not only important, but necessary, because it is evident that only through revenue generation and spread of such information about the benefits it provides to our economy can we better manage this irreplaceable reserved area. This study will also help the respective authorities to develop national policies in correspondence to ecotourism in the country and specifically for the better conservation of SRF so that it can be prolonged and even expanded with time for us and our future generations. In addition, the surplus from the revenues can be used to appoint more skilled and honest officials who will take it to their hearts to truly protect the land from human exploitation and also, improve the infrastructure (without harming the wildlife there) to better accommodate and attract more tourists and cause a positive chain reaction in tourism revenue.

\section{Methodology and Data Collection}

Travel Cost Valuation (TVC) is a popular method when it comes to the question of valuing recreational sites since its inception by Hotelling in 1947. Generally, this method uses the premise that the costs faced by a tourist for a trip to a recreational place (like Sundarbans) can be used as a substitute for the 
recreational value placed by him/her for that place. Islam and Islam (2011) puts it perfectly when they say, "It is his minimum demand price for the recreational service the site is seen to possess." The rate of visitation decreases as the travel cost increases in line with the law of demand. Both a theoretical and a practical analysis of the valuation process of this demand are necessary for estimating the price of the recreational services provided by the site. Also, data on different travel costs and other related social and economic descriptive variables are included in the analysis to approximate a 'recreational demand function.'

To summarize, the study depended dominantly on the primary analysis of the survey questionnaires filled up by tourists who visited the SRF from 14 to 20 August 2015 (7 days). Using the TCV method the recreational demand for SRF was estimated. Secondary research for a comprehensive literature review and background check used relevant websites, articles, papers from famous authors and/or journals and environmental textbooks. In-depth interviews to understand the topic and some short talks with SRF officials were also conducted to get an idea of the prevalent political, social, management and tourist situations. In addition, this research emphasizes on the fact that apart from travel costs, the social and economic conditions of the tourists play significant roles in the determination of such a valuation. Using both primary and secondary sources the research extracts such determinants and mathematically approximates their effect on the recreation demand. As an attempt for a better future for the management and restoration of SRF services it also estimates a revenuemaximizing entry fee. A partially structured questionnaire has been used to collect data (primary source) we need, to establish the functional relationship, then find the site value and suggest an entrance fee, over a period of 7 days (including the weekends Friday and Saturday). The sample has been made as random as possible; of the 4,268 (data obtained from Forest Department office) visitors over the 7 day period, we selected 400 visitors keeping in mind to make them as diverse as possible as per age (only above 18 as children are usually dependents and are not seen to be able to make proper decisions), sex, marital, social and economic statuses, etc. A few of those filled-up questionnaires had to be left out due to

\begin{tabular}{|l} 
Highlighting the immense \\
recreational benefits of the \\
Sundarbans is key, for its better \\
management and conservation. \\
The research found the travel cost \\
of SRF to be approximately 197 \\
million taka per year and proposed \\
an entry fee of 50 tk./person/visit.
\end{tabular}

from Khulna city which is the closest urban area, being problems like inability to finish off due to time constraints, not wanting to continue to finish off the questionnaire if they got cold feet looking at the last few questions, lower levels of understanding or awareness about the site and its amenities (even after the briefing that was given to them) and some other technical glitches like less than 18 years old, same family members and influence by others, and then 300 of the questionnaires were re-selected randomly. EViews software was used to run a regression analysis and establish a relationship between the dependent and independent variables. The actual number of visitors per day (VR) was found out by using a factor of $(4268 / 7) / 300=2.03 \approx 2$.

Here, the areas around SRF have been separated into various zones and the costs of travel from each zone to the site are calculated. The analysis was done by 'regressing' the number of visits (dependent variable) from each zone against the travel costs (independent variable). The cost per visitor per visit used the visitors' willingness to pay for the particular site. The function used is that of Hanley and Spash (1993) and says that the total cost of each visitor ' $i$ ' to visit the particular site ' $\mathrm{j}$ ' can be written as -

$$
\mathrm{Cij}=\mathrm{C}(\mathrm{DC} i \mathrm{j}, \mathrm{TCij}, \mathrm{Ej}), \text { where } \mathrm{i}=1 \ldots . . \mathrm{n} \text {; }
$$

where, $\mathrm{Cij}$ is the total cost for visitor ' $\mathrm{i}$ ' to visit the site ' $\mathrm{j}$ '; DCij is the distance cost for individual ' $\mathrm{i}$ ' which is again a function of the distance from origin of visitor to site and the cost per mile of travelling; TCij is the time cost (includes the value of the visitor's time and the time spent inside the place); $\mathrm{Ej}$ is the entry fee to the place (if it does not exist then $=0$ ).

In addition to this, the recreational use value (V) for each of the designated zones can be estimated using this equation -

$$
\mathrm{V}=[(\mathrm{T} \times \mathrm{w})+(\mathrm{D} \times \mathrm{v})+\mathrm{Ca}] \times \mathrm{Va} \text {; }
$$

where, $\mathrm{T}$ is the travel time (expressed in hours); $\mathrm{w}$ is the mean wage rate (expressed as Tk/hour); $\mathrm{D}$ is the distance between zone and site (expressed in $\mathrm{km}$ ); $\mathrm{v}$ is the marginal vehicle maintenance costs; $\mathrm{Ca}$ is the cost of admission to an asset (may be $=0$ ); $\mathrm{Va}$ is the mean number of visits per year from each zone.

\section{Data Analysis and Results}

only $61 \mathrm{~km}$ away. They had to spend the least (only $502.5 \mathrm{Tk}$. on average) for their travel. An unnatural trend can be observed next with Dhaka visitors being almost $18 \%$ of the total visitors, even though the city is over $240 \mathrm{~km}$ from the site, farther away than other places like Potuakhali and Jessore $(123$ and $127 \mathrm{~km}$ away, respectively) from which 24 and 21 visitors came, respectively to SRF (Table 1). The anomaly with Dhaka data is probably because Dhaka is the capital city and its residents are typically richer and more vacation demanding than other cities. The routes connecting SRF and Dhaka city can also be a factor, because the connecting roads and transportation systems are way better between these two than many closer cities/towns. Same trends can be seen for more 
major cities and semi-urban areas Chittagong, Rajshahi and Sylhet all of which being farther away from SRF have contributed more visitors than their closer counterparts for similar reasons of better incomes (which make them more vacation-inclined) and improved transportation systems and roads. The most was spent by the visitors from Sylhet which is the farthest place recorded in the sample from SRF (over $425 \mathrm{~km})$.

Two more points of significance from the data collected were that most of the visitors were male (over $60 \%$ ) which might mean that females are less attracted to the place due to lowly tourist facilities or because of security reasons or simply because, they were rejecting to complete the questionnaires more than the males, and that Rangamati being closer than its farther counterparts contributed only one visitor; this might be due to the fact that the transportation and road systems between it and SRF are poor or simply, because Rangamati itself is a nature-rich site and hosts a number of parks and sanctuaries. It is also important to note that the anomalistic trend among distance from site, travel costs and visitors' numbers may be simply because the population of each site is not equal and so it is important to take the visitations in terms of overall population from each site to get the true trend. Only a couple of foreigners filled up the questionnaires, but their questionnaires were not taken into account, because their valuation ideas and concept are very different from the country people.

Table 1: DISTRICT WISE TRAVEL COSTS AND OTHER TCVM RELATED DATA

\begin{tabular}{|c|c|c|c|c|}
\hline District & No. of visitors & Distance from SRF $(\mathbf{k m})$ & Total population & Travel cost* (Tk.) \\
\hline Khulna & 75 & 61 & 2354000 & 502.5 \\
\hline Dhaka & 53 & 242 & 13875000 & 1356.2 \\
\hline Potuakhali & 24 & 123 & 1527000 & 708.7 \\
\hline Jessore & 21 & 127 & 2752000 & 800.1 \\
\hline Barisal & 15 & 146 & 2299000 & 978.3 \\
\hline Madaripur & 14 & 176 & 1159000 & 1002.7 \\
\hline Faridpur & 12 & 180 & 1245000 & 1190.0 \\
\hline Chittagong & 10 & 275 & 7519000 & 1780.2 \\
\hline Rajshahi & 9 & 274 & 2583000 & 1702.7 \\
\hline Noakhali & 9 & 211 & 3192000 & 1207.6 \\
\hline Manikgonj & 9 & 225 & 1239000 & 1304.9 \\
\hline Chandpur & 8 & 225 & 2493000 & 1319.0 \\
\hline Pabna & 7 & 229 & 2498000 & 1375.5 \\
\hline Feni & 7 & 254 & 1425000 & 1563.7 \\
\hline Comilla & 5 & 265 & 5308000 & 1690.8 \\
\hline Tangail & 4 & 266 & 3572000 & 1706.7 \\
\hline Kishorganj & 3 & 277 & 2857000 & 1798.8 \\
\hline Sirajganj & 3 & 283 & 3075000 & 1976.4 \\
\hline Brahmanbaria & 3 & 307 & 2807000 & 2007.9 \\
\hline Sylhet & 3 & 427 & 2445000 & 3109.9 \\
\hline Bogra & 2 & 322 & 3375000 & 2278.6 \\
\hline Moulavibazar & 1 & 325 & 1905000 & 2250.8 \\
\hline Mymensing & 1 & 334 & 5047000 & 2340.7 \\
\hline Hobigonj & 1 & 359 & 2069000 & 2498.5 \\
\hline Rangamati & 1 & 317 & 708182 & 2176.6 \\
\hline
\end{tabular}

Next, almost $52 \%$ of the visitors had a monthly income of the $20,000-25,000$ taka range, followed by around $19 \%$ with 15,000 - 20,000 taka monthly incomes. Around $15 \%$ visitors had incomes between 10,000 and 15,000 taka in a month, while the rest of the respondents have monthly incomes above 25,000 taka (Table 2). The lower levels of visitors from the lower income ranges is understandable, because the poorer people cannot afford to go on vacations and usually, spend their incomes on necessities rather than luxuries like nature-watching. The lower number of visitors from the above 25,000 taka might be for two reasons first, because Bangladesh is a developing nation and only a measurable few earn higher income and this was reflected in the records and it can also be because most high-income people prefer visiting foreign countries than their own countries' nature sites.

Table 2: MONTHLY INCOME OF SITE VISITORS

\begin{tabular}{|c|c|c|c|}
\hline Income range (Tk.) & Observed no. of visitors in 7 days (V) & Actual no. of visitors per day (VR) & \% \\
\hline Less than 10,000 & 23 & 46 & 7.67 \\
\hline
\end{tabular}




\begin{tabular}{|c|c|c|c|}
\hline $10,000-15,000$ & 22 & 44 & 7.33 \\
\hline $15,000-20,000$ & 56 & 112 & 18.67 \\
\hline $20,000-25,000$ & 155 & 310 & 51.67 \\
\hline $25,000-30,000$ & 15 & 30 & 5.00 \\
\hline Greater than 30,0000 & 29 & 58 & 9.67 \\
\hline
\end{tabular}

To further the research, the places from which the visitors came from were divided into 5 zones, namely A to E depending on their distances from SRF (Table 3 ): this is why the approach that this study took is also called the zonal approach. From each zone, travel costs were calculated and it was found that the visitors from Zone E, which consisted the places furthest from SRF, had to pay the most (3109.9 Tk.) and there were only 6 visitors (VR) from this site (we must keep in mind that the visitors are not relative to the population of this zone and so any trend cannot be fully justified). We do observe a trend; as the distance increases from Zones A to $\mathrm{E}$, the travel cost shoots up. However, this did not reflect in the relationship between zone distances and VR; the maximum number of visitors was from Zone $\mathrm{C}$ $(\mathrm{VR}=254)$ which holds places $200-300 \mathrm{~km}$ away from SRF. This might be attributable to the fact that this zone contained roads and transportation systems that were better than the rest of the zones. It may also be possible, because this zone boasts the four biggest cities in Bangladesh - Dhaka, Rajshahi, Chittagong and Comilla - the residents of which are richer than the rest of the districts and hence, more 'vacation friendly.' Similar reasons have caused more visitors to visit from Zone B than Zone A (which is much closer). Also, Khulna residents believed that many residents prefer going farther for vacation than just $61 \mathrm{~km}$ and so, they visit site-seeing parks and forests farther away.

To solve the problem of zone wise visitors relative to the population in each, another table was made before the regression analysis on the zones with actual number of visitors as a dependent variable. The research had started off on the premise that there is an inverse relationship between the travel costs and VR. This is why it is more important to get the visitors in terms of the population of each zones and that is why the study holds Table 4. For example, although Zone C shows the maximum number of visitors, this can easily be attributable to the fact that these places have good roads connecting them to Mongla Port directly, because it is not the closest to SRF, neither the cheapest to go from to SRF.

Next, to capture the reality of the relationship that exists between visitations and distance from site (and in turn the travel costs) Table 4 was constructed; as the distance increase from SRF so does the average travel cost. The first zone is the closest and has the least average travel cost of $502.5 \mathrm{Tk}$. only: its visits per 100,000 population is 6.37 , while the least numbers of visitors per 100,000 population is from Zone D which is just second to being the furthest from SRF and has the second-highest average travel cost of $2205.3 \mathrm{Tk}$. (0.11). The anomaly of Zone E with highest average travel cost of 3109.09 (as it's the farthest from site) may be attributable to the fact that these people being from Sylhet city were richer and so more people were able to visit the site even though the respondents lived so far away; Zone D had semi-urban regions only and no big cities.

Table 3: ZONE WISE VISITORS TO SITE

\begin{tabular}{|c|c|c|c|c|c|}
\hline Zone & Distance from site (km) & Population (P) & V & VR & Average Travel Cost (Tk.) \\
\hline A & $0-100$ & 2354000 & 75 & 150 & 502.5 \\
\hline B & $100-200$ & 8982000 & 86 & 172 & 893.1 \\
\hline C & $200-300$ & 49636000 & 127 & 254 & 1459.45 \\
\hline D & $300-400$ & 15911182 & 9 & 18 & 2205.3 \\
\hline E & $400-500$ & 2445000 & 3 & 6 & 3109.9 \\
\hline
\end{tabular}

Table 4: VISITS PER POPULATION FROM DIFFERENT TRAVEL ZONES

\begin{tabular}{|c|c|c|c|c|c|}
\hline Zone & Distance from site (km) & P & V & VR & Visits per P (per 100,000) \\
\hline A & $0-100$ & 2354000 & 75 & 150 & 6.37 \\
\hline B & $100-200$ & 8982000 & 86 & 172 & 1.91 \\
\hline C & $200-300$ & 49636000 & 127 & 254 & 0.51 \\
\hline D & $300-400$ & 15911182 & 9 & 18 & 892.5 \\
\hline E & $400-500$ & 2445000 & 3 & 6 & 0.11 \\
\hline
\end{tabular}




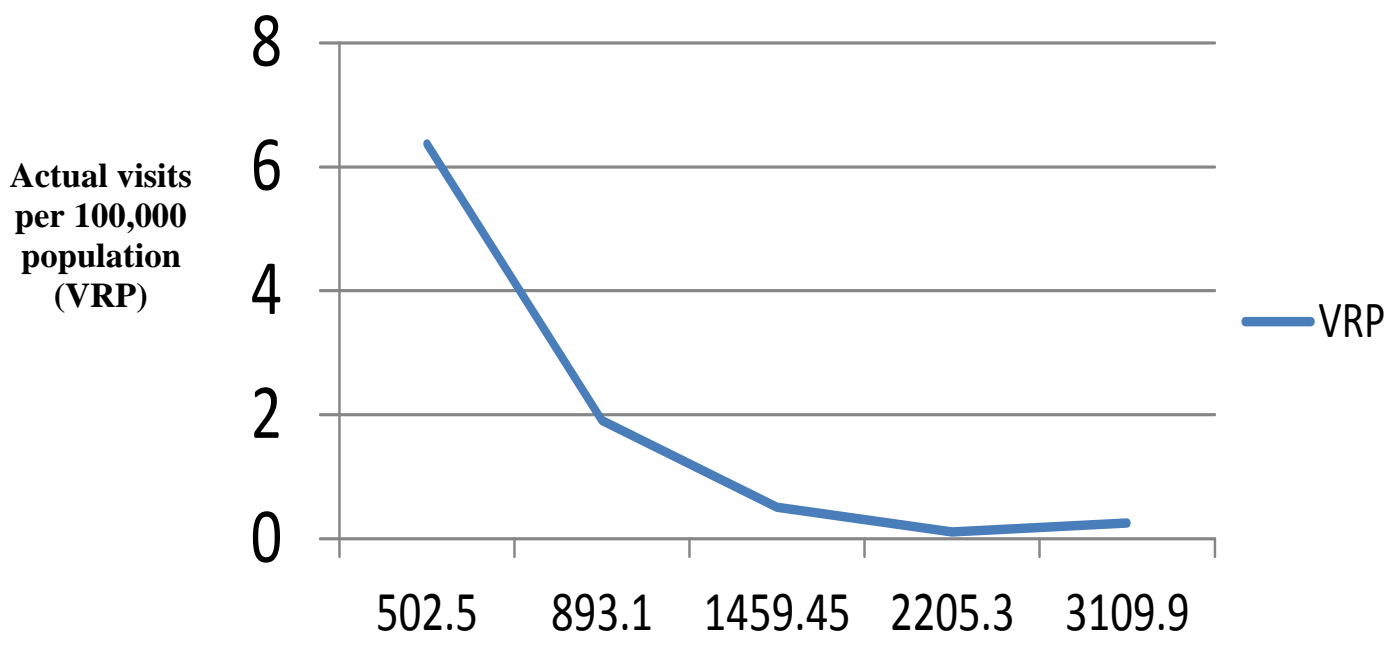

Average Travel Costs (ATC)

Fig. 1: Relationship between VRP and ATC

Through graphical representation (Figure 1) of ATC and VRP data collected, along with regression analysis it was established that a negative relationship exists between VRP and ATC with the following equation -

$$
\mathrm{VRP}=4.93-0.002 \mathrm{ATC} / \mathrm{TC}
$$

The relationship is evidently correlated with an $\mathrm{R}^{2}$ value of 0.56 and the $\mathrm{p}$-value being less than $15 \%$ ( $\mathrm{p}$-value $=$ $0.14)$. The $p$-value is larger than expected, because of the aforementioned Zone E anomaly.

Using the data collected by the study we find that Zone $\mathrm{C}$ boasts the maximum value of the environmental assets of SRF at 111,213,900 Tk. followed by Zones B and A at 46,083,960 Tk. and 22,612,500 Tk., respectively, in a year. The total value of the environmental resources of the whole of SRF is estimated to be 197,416,800 Tk. (around 197

\section{Suggestions}

There are several advises and suggestions that can be proposed from the things and attitudes observed when performing the study. Starting from the resources management of SRF, to the importance of awareness of general public about its need to be preserved for them to pressurize the national and international policy makers to emphasize on proper planning and implementation for its conservation, to the evident requirement of an entry fee (which is separate from the fee paid to take permission (permission fee) from Forest department), many things need to be fixed at this site and beyond.

From the literature reviewed what is clear is that SRF provides natural protection to the coastal zones from tidal waves and the destructive nature of cyclones (which is a common phenomenon in Bangladesh), especially during the monsoon seasons. It is unfortunate, however, that as a result million taka) each year through this study. We must note here that the SRF is usually inaccessible almost 2 out of 12 months of the year due to weather conditions; hence, 300 days were counted.

Lastly, an overwhelming $92 \%$ have suggested an entry fee of $50 \mathrm{Taka} / \mathrm{visit} /$ person and so, that is also the suggestion of the study; initiate an entry fee of 50 Taka for every person every time they enter, the proceeds from which would be around $50 \times 100,000$ visitors per year $=5,000,000$ Taka yearly and can go to the tourist facilities and conservation management improvement of Sundarbans. Fortunately, for the study SRF is the lone destination of the people who come to visit here and so their WTP opinion is only proposed for this particular site and no others that they might visit with the same entry fee or within the same vacation time.

of increased agricultural irrigation, industrialization and change of water route due to the Indian Farakka Barrage (in the mid-1970s), the ecosystems of SRF are threatened as both salinity and siltation levels are increasing rapidly. These have already led and are leading to the ultimate and depressing extinction of the Sundari trees which are the primary flora species of SRF. Added to this is the resultant top-dying disease problem faced by management from the Goran species of flora too. Most environmentalists and environment enthusiasts are of the opinion that the Ganges water sharing issue is not just a geo-techno-political one; it is more a humanitarian issue. It is important to solve this as soon as possible, before more permanent damage to SRF occurs, through educational awareness and interaction between the concerned states, people and corporations that play significant roles in its destruction and management.

The aim of this paper was also to recall and emphasize on the management problems and lack of proper monitoring at the implementation levels to better conserve the 
ecosystems of SRF. The contributions of this great mangrove forest and its habitants are so great that it is indeed wrong to put a value on it. However, most people and definitely local and global decision makers understand better the speech of money and hence, the valuation. It is equally important for the schools and other educational institutions, along with the government (who have conflicting views as they can use the revenue allocated for conserving SRF for more short-term productive economic activities) to spread the awareness about the 'going-ons' in SRF and its importance in the local and global environmental management. Only with added pressure from the general public will the relevant development institutions and concerned states take the initiative to solve the political, geographical and technical problems and look beyond their own use-values and egos to better the management and conservation attempts of the SRF.

This leads on to the most important and last suggestion of the paper - the introduction of a distinct, separate and most importantly, revenue maximizing (and 'non-visitation declining') entry fee. An entry fee of Tk 50/person/visit is suggested as an astounding $92 \%$ of the respondents in the study have suggested so, instead of the zero entry fees that they are used to now. It is a general believe that increasing the fee above 50/- will cause a decline in the visitation levels to SRF because Bangladesh has just promoted itself into a middle income country with most still living in the lower class levels. About $2 \%$ of the respondents consisted of people who said point black that no entry fee policy should persist, because it is a place of nature and should be free to see for everybody and anybody; rest of the respondents (consisting mostly of rich, non-resident Bangladeshis and higher-income people) proposed entry fees of more than 50 Taka, but less than 100, probably because they are able to afford it themselves, and such a low fee would not affect their visitation interest to a grand place like the Sundarbans.

The proposed entry fee would be able to generate a total revenue of 50/- x 100,000 (the usual visits per year) = 5000000/- (5 million taka) which can go into better management development plan for SRF. It is also important to take note that the entry fee can increase progressively when the revenue generated are used efficiently to better the facilities present at SRF and develop it for ecotourism prospects. Also, better, skilled and most importantly wellpaid Forest Department officials can be appointed to important posts, who would be expected to better monitor the conservation of SRF. Some of these funds can be used for two more purposes - diverting the livelihoods of locals to something rather than those that destroy forests like cutting wood, and building better tourist facilities. The former purpose would better the lifestyles of some of the locals and conservation attempts of management. The latter purpose would cause a positive chain reaction by attracting more tourists to the place, rather than the ones who brave this visit now, and help earn more revenue and spread the world of Bangladesh's beautiful ecotourism spot, the Sundarbans Reserved Forest.

\section{v. Conclusion}

As SRF is such a place which provides value to the world on the whole by being an ecologically balanced recreational site, a diverse ecosystem for hundreds of (and even unique) species of flora and fauna, provides protection from increased disaster destruction and moderates climate change and is a commercially important site in terms of ecotourism and business values (timber, medicines, fisheries, etc.), an efficient valuation method is a must to calculate a value for its assets, and that is what this study has done through the TCV approach. This study revealed that there is huge potential for both managerial and conservational improvements, as well as ecotourism facilities' building and for that an entry fee of $50 \mathrm{Tk} /$ person/visit is proposed which would produce revenue of 5,000,000 Tk/year. In addition to this, a recreational demand function has been successfully used to establish a relationship between visitation rates and travel cost, which in turn was used to determine the WTP of visitors. Also, a total value of 197 million taka per year was estimated for the total asset values of SRF. Furthermore, the need to attract the relevant authorities' attention on developing the ecotourism and conservation management policies for SRF and later, other national parks and sanctuaries was also addressed in the research, which is a must for a better environmental future for us all.

\section{Acknowledgment}

The author would like to acknowledge her supervisors and faculty members at Durham University, UK's Business school, the officers at the Khulna port and respondents at Sundarbans, without all of whom the research would be incomplete.

\section{References}

[1] Farnham T. J., (2007). Saving Nature's Legacy: Origins of the Idea of Biological Diversity. USA: Yale University Press.

[2] Guha, I. and Ghosh, S. (2009). A Glimpse of The Tiger: How Much Are Indians Willing To Pay For It? South Asian Network for Development and Environmental Economics (SANDEE). Kathmunda, Nepal. Working Paper 39-09.

[3] Hanley, N. and Spash, C.L. (1993). Cost-Benefit Analysis and the Environment. The Economic Journal. Royal Economic Society and Wiley Publishers. Vol. 104, No. 427 (Nov., 1994), pp. 1488-1490.

[4] Islam, K.M.N and Islam, M.N. (2011). Economics of Extraction of Products from Sundarbans Reserve Forest. Bangladesh Journal of Agricultural Economics. XXXIV, 1\&2 (2011) 29-53.

[5] Mukul S. A., (2007). Biodiversity Conservation Strategies in Bangladesh: The State of Protected Areas. Tiger paper. Vol. 34: No. 3 .

[6] Rana M. P., Sohel M.S.I, Mukul S. A., Chowdhury M. S. H., Akter S., Koike M., (2010). 'Implications of ecotourism development in protected areas: a study from Rema-Kalenga wildlife sanctuary, Bangladesh'. Journal of Biogeosciences and Forestry, 3: 23-29.

[7] Reeves R. R., (2000). The Value of Sanctuaries, Parks, and Reserves (Protected Areas) as Tools for Conserving Marine Mammals. Final Report to the Marine Mammal Commission, Marine Mammal Commission, Bethesda, MD.

[8] Additional Sources: Short interviews with Forest Department officials, Khulna (August 2015).

\begin{tabular}{|c|c|}
\hline & Raisa Bashar \\
Lecturer \\
Environmental Science and Management \\
North South University \\
MS in Environmental and Natural Resource \\
Economics \\
Durham University, UK
\end{tabular}

